\title{
Experimental infection of the fly Calliphora vicina with the trypanosomatid Angomonas deanei and cross-infection between different calliphorid species
}

\author{
Anna I. Ganyukova, Marina N. Malysheva and \\ Alexander O. Frolov \\ Zoological Institute, Russian Academy of Sciences, 199034 St. Petersburg, Russia
}

| Submitted April 4, 2021|Accepted May 21, 2021|

\begin{abstract}
Summary
In this study, we present the results of an experimental infection of larvae and imagoes of the fly Calliphora vicina with the trypanosomatids Angomonas deanei from two laboratory cultures (A. deanei $\mathrm{MN}$ and $A$. deanei TCC036E). In accordance with our results, the rectum of an adult fly is the main site of the parasites localization where they form massive clusters, while no persistent infection develops in the intestines of the larvae. Horizontal transmission between imagoes of $C$. vicina was demonstrated in both cases of the infection: with $A$. deane $i \mathrm{MN}$ and $A$. deane $i \mathrm{TCC} 036 \mathrm{E}$. In a series of experiments on the transmission of $A$. deanei $\mathrm{MN}$ between three species of flies (Calliphora vicina, Lucilia sericata, and Protophormia terraenovae), we demonstrated successful infection between the flies of different species.
\end{abstract}

Key words: Trypanosomatidae, symbiont-harboring trypanosomatids, Angomonas deanei, parasites of Diptera, host-parasite relationships

\section{Introduction}

Trypanosomatids (Kinetoplastea: Trypanosomatidae) are the obligate parasitic flagellates widespread throughout the world, many of which cause dangerous infections of invertebrate and vertebrate animals (including humans) and plants. They have important economic and epidemiological impacts. Traditionally, trypanosomatids are divided into two non-systematic groups based on their life cycles. In dixenous trypanosomatids, an invertebrate and vertebrate host (or an invertebrate host and a flowering plant) alternate during the parasite's life cycle. Monoxenous trypanosomatids, on the contrary, realize their life cycles only in the invertebrates.

The host specificity of monoxenous trypanosomatids is a subject of considerable interest of researchers in recent years. For a long time, the "one host - one parasite" paradigm, in accordance with which the relationship of parasites with their hosts was regarded as strictly species-specific parasitism, has been dominating in the research area of parasitic protists (Wallace, 1966; Podlipaev, 1990; Votýpka et al., 2015). Since the morphological characters of trypanosomatids, which are revealed using light microscopy, are extremely scarce, the fact of the discovery of trypanosomatids in a new host was 
often considered a reason for describing new species and genera.

However, with the progress of molecular genetic methods, it became obvious that this concept was wrong. It was revealed that a number of trypanosomatids, such as the recently described genera Jaenimonas, Sergeia, Paratrypanosoma (Svobodová et al., 2007; Flegontov et al., 2013; Hamilton et al., 2015), despite the apparent external similarity with representatives of the typical genera of monoxenous trypanosomatids, e.g. Herpetomonas or Crithidia, are the separate evolutionary branches. Moreover, the genus Paratrypanosoma, which currently includes only one species $P$. confusum, was positioned at the base of the phylogenetic tree of the entire family (Flegontov et al., 2013).

At present, based on molecular data it is clear that the level of specificity of trypanosomatids varies widely, from strict to very broad, and can significantly differ between species (Týč et al., 2013; Votýpka et al., 2015; Frolov et al., 2021).

Angomonas deanei (Carvalho, 1973), which belongs to the symbiont-harboring trypanosomatids of the subfam. Strigomonadinae, is one of the widespread species, noted in different insect hosts. This species was first isolated from the intestines of the predatory bug Zelus leucogrammus (Hemiptera, Reduviidae) in Brasil (stain TCC036E) (Carvalho, 1973; Teixeira et al., 2011), but later it was repeatedly found in flies of the fam. Calliphoridae and Sarcophagidae all over the world (Týč et al., 2013; Ganyukova et al., 2017; Borghesan et al., 2018).

We previously demonstrated that $A$. deanei isolate MN obtained in 2017 from the rectum of Lucilia sp. in the northwest of the Leningrad region (Ganyukova et al., 2017), successfully realizes its life cycle in the rectum of the adult $L$. sericata (Ganyukova et al., 2020a). This work is a continuation of the previous studies; it aims to unveil the possibility of interspecies transmission of this parasite.

\section{Material and methods}

\section{CULTIVATION OF TRYPANOSOMATIDS}

Axenic cultures $A$. deanei $\mathrm{MN}$ and $A$. deanei TCC036E were maintained in the bank of cultures at the Zoological Institute RAS (Malysheva et al., 2016) using the M199 medium without antibiotics, at the temperature of $22^{\circ} \mathrm{C}$, and transplanted every 14 days.

\section{MAINTENANCE OF INSECTS}

To study the parasites life cycle, we used the larvae and imagoes of the fly Calliphora vicina.

Uninfected larvae for experiments were obtained as follows. We collected pieces of beef liver with $C$. vicina eggs oviposited overnight. Then we removed the pieces with eggs and placed them into $1 \mathrm{~L}$ glass jars covered with gauze for aeration at the temperature of $22^{\circ} \mathrm{C}$ and $16 \mathrm{~L} / 8 \mathrm{D}$ photoperiod. Wet sawdust was used as a substrate. On the next day, we got one-day instar larvae. Later, the larvae were kept under the same conditions (Vinogradova and Reznik, 2013).

We used imagoes of $C$. vicina to study the life cycle of the parasite.

For cross-infections, we used imagoes of three species of flies: Calliphora vicina, Lucilia sericata, and Protophormia terraenovae. These insects have been cultivated for many years and are regularly reclaimed in the Laboratory of Insect Biopharmacology and Immunology of Saint-Petersburg State University.

All imagoes were kept in plastic containers L10 $\times \mathrm{H} 15 \times$ W7 $\mathrm{cm}$ with a perforated lid at $22{ }^{\circ} \mathrm{C}$ and 16L/8D photoperiod (Vinogradova and Reznik, 2013). Troughs with drinking water and a lump of sugar for insects' feeding were kept in the containers during the whole time of the experiments. Adult flies received no protein nutrition.

The insects were kindly provided by A.P. Nesin (Laboratory of Insect Biopharmacology and Immunology, Department of Entomology, SaintPetersburg State University).

\section{INFECTION OF CALLIPHORA VICINA LARVAE}

The $C$. vicina larvae were transferred to the Petri dishes of $6 \mathrm{~cm}$ in diameter on a moist nutrient substrate, which consisted of laboratory culture of parasite $\left(3 \times 10^{8}\right.$ cells $\left./ \mathrm{ml}\right)$ and baby food "Baby puree FrutoNyanya from beef" (JSR "PROGRESS") mixed at a 1:3 ratio. The infection was carried out according to two patterns. (1) Short-term infection: 1-day larvae were kept on the infected substrate during $10 \mathrm{~min}$ and then moved onto a normal nutrient substrate (the moment of moving was referred to as time zero). (2) Long-term infection: 
1-day larvae were kept on the infected substrate, which was daily renewed, until the insects' pupation. Then the larvae were dissected at regular intervals.

INFECTION OF IMAGOES OF CALLIPHORA VICINA, LUCILIA SERICATA, PRotophormia teRraenovaE

Just before the infection, we kept insects without food and water for $24 \mathrm{~h}$. Then the flies were placed in separate Petri dishes of $35 \mathrm{~mm}$ in diameter, where $15 \mu \mathrm{l}$ of the laboratory culture of the parasite $\left(3 \times 10^{8}\right.$ cells $/ \mathrm{ml}$ ) were added. After the fly finished drinking, the volume of the remaining drop was measured using a dispenser. The average volume of liquid drunk by one fly was about $10-15 \mu$. The moment the fly finished drinking was referred to as time zero.

Prolonged immobilization of CALLIPHORA VICINA IMAGOES

As part of the experiment to determine the duration of infection of the flies, infected 1-day imagoes (after emerging from puparia) were placed in plastic tubes (Kostygov et al., 2020) after single infection. The front opening of the tube was covered with gauze with a mesh size of $\sim 1 \mathrm{~mm}$. The mesh size allowed the insect to pull the proboscis and receive the $15 \%$ sugar syrup from the external drinking trough.

The trough with sugar syrup was daily renewed. The back of the tube containing the fly was plugged with a piece of cotton wool, which did not allow the fly to move along the longitudinal axis of the tube and absorb the insect feces. The cotton wool was changed daily. The movement of insects in the tubes was limited, which excluded the possibility of autoinvasion of flies through their own feces.

Transmission of InFeCtion BETWEen CALLIPHORA VICINA IMAGOES

We tested the adult-adult transmission by co-housing of 5 uninfected flies of C. vicina and 3 infected flies of the same species. All these insects were dissected and screened for trypanosomatids by light microscopy after 5 days of cohabitation in the container. To differentiate flies from each other we clipped a wing of the infected fly. We carried out 4 replications of the transmission experiment for A. deanei $\mathrm{MN}$ (4 vials in total contained 20 flies of uninfected group) and 6 replications for $A$. deanei TCC036E (6 vials in total contained 30 flies of uninfected group).

\section{INTERSPECIES CROSS-INFECTIONS}

We tested interspecific adult-to-adult transmission by keeping 5 uninfected flies of one species and 3 flies of another species (which have been previously infected with the $A$. deanei $\mathrm{MN}$ ) together. All these insects were dissected and screened for trypanosomatids by light microscopy after 5 days of cohabitation in the container. We performed 6 replicates for cross-infections in the line " $C$. vicina $\leftrightarrows$ L. sericata" (6 vials in total contained 30 flies of uninfected group for each species) and 3 replicates for cross-infections in the line " $L$. sericata $\leftrightarrows P$. terraenovae" ( 3 vials in total contained 15 flies of uninfected flies for each species).

\section{DisSECTION OF INSECTS}

The insects were euthanized with chloroform vapors and dissected in a drop of physiological saline. The intestines were examined under a Leica DM2500 microscope (Leica Microsystems, Wetzlar, Germany). Isolated intestine fragments including their contents were studied for infection. Isolated parts of the digestive tract were studied separately.

\section{Results}

\section{The course of infection of $A$. deanei $\mathrm{MN}$ and $A$. deanei TCC036E in the $C$. vicina}

\section{INFECTION OF C. VICINA LARVAE}

During the first 30 min after the infection with trypanosomatids, both $A$. deanei $\mathrm{MN}$ and $A$. deanei TCC036E were observed only in the foregut and the crop of the fly larvae (Table 1). Over the next two hours, they spread throughout the intestine, including the hindgut. Over the next two days, we found individual cells of trypanosomatids in the midgut and hindgut of the larvae, but we have never noted mass clusters of flagellates. We did not find even single cells of parasite in larvae dissected on the 3rd and 5th days from the moment of infection.

The purpose of the next experiment was to identify the ability of parasites' development in the digestive tract of larvae during long-term invasion. During the first 5 days, we observed individual cells in the intestines of the larvae (Table 2). On the 6-7th day, at the post-feeding stage, the number of 
Table 1. Short-term single infection of 1-day larvae of the fly Calliphora vicina.

\begin{tabular}{|l|l|l|l|}
\hline \multirow{2}{*}{ Time after infection } & \multicolumn{2}{|c|}{ Angomonas deanei } & \multirow{2}{*}{ Site of infection } \\
\cline { 2 - 3 } & TCC036E & MN & Foregut/crop \\
\hline $5-30 \mathrm{~min}$ & Dis $9 / \mathrm{Inf} 9 *$ & Dis $9 / \mathrm{Inf} 9$ & Foregut/crop, midgut, hindgut \\
\hline $30 \mathrm{~min}-2 \mathrm{~h} 30 \mathrm{~min}$ & Dis $10 / \mathrm{Inf} 10$ & Dis $11 / / \mathrm{nf} 11$ & Midgut, hindgut (several cells) \\
\hline $4-24 \mathrm{~h}$ & Dis $10 / \mathrm{Inf} 10$ & Dis $10 / \mathrm{Inf} 10$ & Midgut, hindgut (several cells) \\
\hline $1-2$ days & Dis $10 / \mathrm{Inf} 5$ & Dis $10 / \mathrm{Inf} 4$ & Uninfected \\
\hline 3 days & Dis $8 / \mathrm{Inf} 0$ & Dis $7 / / \mathrm{nf} 0$ & Uninfected \\
\hline 5 days & Dis $9 / \mathrm{Inf} 0$ & Dis $10 / \mathrm{Inf} 0$ & \\
\hline
\end{tabular}

* Dis - dissected, Inf - infected flies

infected individuals decreased significantly, and on the 8th day after the infection, we did not notice a single infected larva at the pre-puparium stage. We also did not observe infections among adults that emerged from the formed puparia.

\section{INFECTION OF $C$. VICINA IMAGOES}

We assessed the dynamics of infection development in imagoes of $C$. vicina. Five minutes after the infection, we observed flagellates in the foregut, crop, and the initial sections of the midgut (Table 3 ). During the first hour, trypanosomatids spread to the hindgut. After $4 \mathrm{~h}$, trypanosnomatids finally left the foregut. During the first day, we observed flagellates in the gut of insects, but their number in the midgut gradually decreased, while in the hindgut, especially in the rectum, their number increased significantly from single cells to numerous "pile carpets" over the entire surface of the rectum cuticle. About a day after the infection, we observed massive clusters of flagellates in the insect rectum, especially in the area of the rectal glands.

DURATION OF FLAGELLATES' PERSISTENCE IN THE FLY'S RECTUM

We placed the flies in plastic tubes with the diameter of $5 \mathrm{~mm}$ immediately after the infection to isolate the infected flies from other insects and excluded the possibility of movement of the fly itself as it previously published (Ganyukova et al., 2020a). We kept 30 infected adults and 30 control flies in the immobilization conditions. The lifespan of the flies both in the infected and in the control groups is described by a declining linear graph (Fig. 1). The maximum lifespan of the flies infected by A. deanei TCC036E was 16 days, and of the flies infected by $A$. deanei $\mathrm{MN}-17$ days. The maximum lifespan of the flies from the control group under the same conditions was 18 days. Dissection of insects removed from the tubes within a few hours after death showed that the infection persisted throughout the entire life of the infected insect.

\section{HorizOnTAL TRANSMISSION AMONG $C$. VICINA IMAGOES}

We carried out experiments on infection transmission between adult flies of $C$. vicina by cohousing of 5 uninfected flies with 3 infected flies of the same species. In the case of $A$. deanei $\mathrm{MN}$, the infection was successfully transmitted in 11 out of 17 insects (64.7\%), for $A$. deanei TCC036E, only 8 of the 29 insects involved in the experiment were infected as a result $(27.6 \%)$ (3 flies from the first experiment and 1 fly from the second died on the first day after the start of the experiment and were not included in the final sample).

Table 2. Long-term infection of 1-day larvae of Calliphora vicina.

\begin{tabular}{|l|c|c|}
\hline \multirow{2}{*}{ Age } & \multicolumn{2}{c|}{ Angomonas deanei } \\
\cline { 2 - 3 } & TCC036E & MN \\
\hline 3-days larvae & Dis $10 / \mathrm{Inf} 10 *$ & Dis $10 / \mathrm{Inf} 10$ \\
\hline 5-days larvae & Dis $10 / \mathrm{Inf} 8$ & Dis $10 / \mathrm{Inf} 9$ \\
\hline 6-7-days larvae (post-feeding stage) & Dis $10 / \mathrm{Inf} 2$ & Dis $10 / \mathrm{Inf} 1$ \\
\hline 8-days larvae (pre-pupal stage) & Dis $10 / \mathrm{Inf} 0$ & Dis $10 / \mathrm{Inf} 0$ \\
\hline Imagoes & Dis $10 / \mathrm{Inf} 0$ & Dis $10 / \mathrm{Inf} 0$ \\
\hline
\end{tabular}

* Dis - dissected, Inf - infected flies 


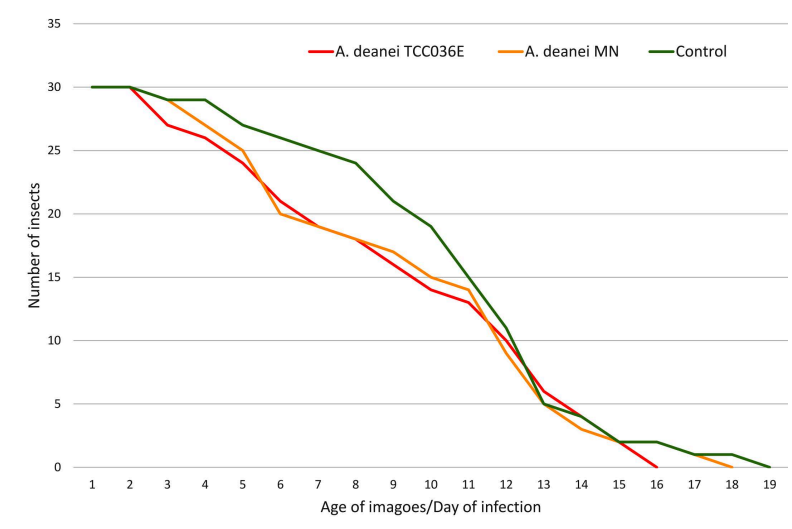

Fig. 1. The lifespan of infected and uninfected C. vicina imagoes during the immobilization experiment.

\section{Interspecies cross-infections}

We conducted series of experiments on horizontal transmission of $A$. deanei $\mathrm{MN}$ infection between different species of flies: $C$. vicina $\leftrightarrows L$. sericata and $L$. sericata $\leftrightarrows P$. terraenovae. The results showed that cross-infections was successful in all cases (Tables 4,5 ). The success rate of parasite transmission from C. vicina to L. sericata was $63.3 \%$ of cases. The reverse transmission from infected $L$. sericata to C. vicina was $70 \%$. In the second line of the experiment, $60 \%$ of $L$. sericata were infected from $P$. terraenovae and $46.7 \%$ of $P$. terraenovae got the infection from L. sericata.

\section{Discussion}

In this work, we demonstrated that two isolates of the trypanosomatids Angomonas deanei obtained at different times from Zelus leucogrammus (Hemiptera, Reduviidae) (A. deanei TCC036E) and the calliphorid fly Lucilia sp. (Diptera, Calliphoridae) (A. deanei $\mathrm{MN}$ ), are able to successfully realize their life cycles in the rectum of the adult Calliphora vicina flies (Diptera, Calliphoridae). Earlier, we showed that $A$. deanei could use the imagoes of $L$. sericata as the host and realize their life cycles in the rectum of the fly (Ganyukova et al., 2020a). An interesting fact is that the isolate $A$. deanei TCC036E, obtained from the reduviid bug about 50 years ago and during all this time cultivated under laboratory conditions, also successfully formed a stable infection in the rectum of C. vicina. In general, the chronology of the infection development, as well as the localization of the parasites from both isolates in the intestine of C. vicina correspond to the data that we published earlier for L. sericata (Ganyukova et al., 2020a).

We confirmed the horizontal transmission of the infection among the adults of $C$. vicina in the cases of both isolates; however, the percentage of insects infected during the experiment differed almost twofold: for $A$. deanei $\mathrm{MN}$ it was $64.7 \%$, while for A. deanei TCC036E it was only $27.6 \%$. Apparently, these differences can be associated with long-term cultivation of the second isolate; however, this issue requires further careful study.

None of the isolates used in the experiments were able to form a stable infection in the intestines of $C$. vicina larvae. This finding is consistent with our previous results for L. sericata larvae (Ganyukova et al., 2020a). Meanwhile, cases of successful infection of fly larvae and trans-phase transmission of infection (despite the complex morphological and metabolic rearrangements of the host during the pupal stage) are known in the literature. For example, Jaenimonas drosophilae forms large clusters in the midgut of Drosophila falleni larvae and persists during metamorphosis in the "yellow body" - an aggregation of cells of the larval intestine (Hamilton et al., 2015). It was also noted that the biflagellate trypanosomatid described as " $H$. muscarum" is able to occupy the midgut of eye gnat Hipellates pusio larvae (Bailey and Brooks, 1972a, 1972b). Subsequently, the parasites penetrate the intestinal wall and enter the haemocoel of the larvae. Some of these infected larvae die, but some

Table 3. Infection dynamics in the digestive tract of imagoes of Calliphora vicina.

\begin{tabular}{|l|c|c|c|}
\hline \multirow{2}{*}{$\begin{array}{c}\text { Time after } \\
\text { infection }\end{array}$} & TCC036E & MN & \multirow{2}{*}{ Site of infection } \\
\cline { 2 - 3 } & Dis $10 / \mathrm{Inf} 10^{*}$ & Dis $10 / \mathrm{Inf} 10$ & Foregut/crop, midgut \\
\hline $30 \mathrm{~min}$ & Dis $14 / \mathrm{Inf} 14$ & Dis $12 / \mathrm{Inf} 12$ & Foregut/crop, midgut, hindgut \\
\hline $4-24 \mathrm{~h}$ & Dis $17 / \mathrm{Inf} 17$ & Dis $15 / \mathrm{Inf} 15$ & Midgut, hindgut \\
\hline $1-2$ days & Dis $14 / \mathrm{Inf} 14$ & Dis $12 / \mathrm{Inf} 12$ & Hindgut \\
\hline
\end{tabular}

* Dis - dissected, Inf - infected flies 
Table 4. Cross infections between C. vicina and L. sericata.

\begin{tabular}{|c|c|c|}
\hline \multirow{2}{*}{$\begin{array}{c}\text { Infected } \\
\text { donor species }\end{array}$} & \multicolumn{2}{|c|}{ Acceptor species } \\
\cline { 2 - 3 } C. vicina & & L. sericata \\
\hline L. sericata & $\begin{array}{c}\text { Dis } 30 / \operatorname{lnf} 21 \\
(70 \%)\end{array}$ & $\begin{array}{c}\text { Dis } 30 / \text { Inf } 19 * \\
(63,3 \%)\end{array}$ \\
\hline
\end{tabular}

* Dis - dissected, Inf - infected flies

undergo metamorphosis with the preservation of the infection. Both of these parasites $-J$. drosophilae and " $H$. muscarum" - are capable of trans-phase transmission of the infection and affect the success of the further development of imagoes (Hamilton et al., 2015; Bailey and Brooks, 1972b).

We believe that two main assumptions can explain why $A$. deanei is only able to persist for a short time in the intestines of calliphorid larvae. The first one is associated with the action of antimicrobial peptides and a variety of insect immune pathways (Hu and Aksoy, 2006; Hamilton et al., 2015), which can inhibit the development of the infection. The second assumption, which seems the most probable, is based on the fact that the hindgut of larvae differs from that of adults: it is an elongated tube that does not have a pronounced expansion (rectal ampulla/rectum) and is devoid of rectal glands (Lowne, 1890-1892; Fox et al., 2010). Probably, it is the inability to gain a foothold in the gut of the larva due to its anatomical features, coupled with physico-biochemical conditions (that differ from the adult hindgut), that are the main reason why stable infection of $A$. deanei does not develop in the digestive tract of larvae.

Our experiments on the interspecies transmission of $A$. deanei among adult flies showed that these parasites are not selective with respect to hosts, and thus they can be transmitted among imagoes of at least three different calliphorid species: C. vicina, $L$. sericata, and $P$. terraenovae. The fact that the full life cycle of $A$. deane i is successfully realized in the rectum of $C$. vicina or L. sericata, as well as the ability of these parasites to persist throughout the life of the host, have been confirmed already (Ganyukova et al., 2020a). Flagellates intensively infect the surface of the rectum of $P$. terraenovae, which indicates the active proliferation of the parasites in this host.

It is not clear whether $A$. deanei can expand to other taxonomic groups of insects. This flagellate was originally found in the intestine of the reduviid bug
Table 5. Cross infections between L. sericata and $\mathrm{P}$. terraenovae.

\begin{tabular}{|c|c|c|}
\hline \multirow{2}{*}{$\begin{array}{c}\text { Infected } \\
\text { donor species }\end{array}$} & \multicolumn{2}{|c|}{ Acceptor species } \\
\cline { 2 - 3 } & L. sericata & P. terraenovae \\
\hline L. sericata & & $\begin{array}{c}\text { Dis } 15 / \text { Inf } 7 * \\
(46,7 \%))\end{array}$ \\
\hline P. terraenovae & $\begin{array}{c}\text { Dis } 15 / \mathrm{Inf} 9 \\
(60 \%)\end{array}$ \\
\hline
\end{tabular}

* Dis - dissected, Inf - infected flies

Z. leucogrammus (Carvalho, 1973); however, it was later found only in dipteran hosts (Týč et al., 2013; Ganyukova et al., 2017; Borghesan et al., 2018). This situation is not unique: among trypanosomatids, it is quite common for some species to be found in both dipteran and hemipteran hosts. H. samuelpessoai once was also isolated from the bug Zelus sp., but later it was found only in Diptera (Borghesan et al., 2013).

Perhaps these are occasional single examples when a predatory bug, as a result of feeding on an infected victim, becomes a host of a parasite inherent in another taxonomic group of insects. In this case, predatory bugs, being active predators, can play the role of an active "collector" of parasites of their victims. However, it is not clear how often temporary or permanent host-parasite associations can occur among such accidental infections. An example of trypanosomatids, which are characterized by extremely wide host radiation, is the Palearctic species Crithidia brevicula. This trypanosomatid appears to be a universal parasite capable of infecting and realizing its life cycle in bugs of the families Nabidae, Gerridae and nonpredatory Miridae (Malysheva and Frolov, 1995; Kostygov et al., 2014), as well as various Diptera: mosquitoes Culex spp. and flies of the families Calliphoridae, Muscidae, Heleomyzidae, Sepsidae and Antomyidae (Schoener et al., 2018; Ganyukova et al., 2020b).

To conclude, $A$. deane $i$ is a widespread parasite that can successfully spread by horizontal transmission among the imagoes of various fly species. The rectum of the imago is the main site of localization of the parasite, where it persists throughout the entire life of the host. Despite the fact that the A. deanei TCC036E isolated from the predatory bug is capable of developing in flies and being transmitted between adult flies, the question of whether this parasite is able to carry out its life cycle in the intestines of a hemipteran host is still open. 


\section{Acknowledgements}

This work was supported by the Russian Foundation for Basic Research (https://www.rfbr.ru) grant 19-34-90027 to AIG and AOF. The research was carried out using the equipment of the Core Facilities Centre "Taxon" at the Zoological Institute, Russian Academy of Sciences (St. Petersburg, Russia).

\section{References}

Bailey C.H. and Brooks W.M. 1972a. Histological observations on larvae of the eye gnat, Hippelates pusio (Diptera: Chloropidae), infected with the flagellate Herpetomonas muscarum. J. Invertebr. Pathol. 19 (3), 342-353.

Bailey C. H. and Brooks W. M. 1972b. Effects of Herpetomonas muscarum on development and longevity of the eye gnat, Hippelates pusio (Diptera: Chloropidae). J. Invertebr. Pathol. 20 (1), 31-36.

Borghesan T.C., Ferreira R.C., Takata C.S., Campaner M., Borda C.C., Paiva F., Milder M.V., Teixeira M.G. and Camargo E.P. 2013. Molecular phylogenetic redefinition of Herpetomonas (Kinetoplastea, Trypanosomatidae), a genus of insect parasites associated with flies. Protist. 164 (1), 129-152.

Borghesan T.C., Campaner M., Matsumoto T. E., Espinosa O.A., Razafindranaivo V., Paiva F., Carranza J.C., Acez N., Neves L., Teixeira M.M.G. and Camargo E.P. 2018. Genetic diversity and phylogenetic relationships of coevolving symbiontharboring insect trypanosomatids, and their Neotropical dispersal by invader African blowflies (Calliphoridae). Front. Microbiol. 9, 131.

Carvalho A.L.M. 1973. Estudos sobre a posição sistemática, a biologia ea transmissão de tripanosomatídeos encontrados em Zelus leucogrammus (Perty, 1834) (Hemiptera, Reduviidae). Rev. Pathol. Trop. 2, 223-274.

Flegontov P., Votýpka J., Skalický T., Logacheva M.D., Penin A.A., Tanifuji G. and Lukeš J. 2013. Paratrypanosoma is a novel early-branching trypanosomatid. Curr. Biol. 23, 1787-1793.

Fox D. T., Gall J. G. and Spradling A. C. 2010. Error-prone polyploid mitosis during normal Drosophila development. Genes Dev. 24 (20), 2294-2302.

Frolov A. O., Kostygov A. Y. and Yurchenko V. 2021. Development of monoxenous trypanosomatids and phytomonads in insects. Trends Parasitol. 37 (6), 538-551.
Ganyukova A.I., Malysheva M.N. and Frolov A.O. 2017. Angomonas deanei (Kinetoplastida: Trypanosomatidae) in the fly Lucilia sp. (Diptera: Calliphoridae): description and cultivation of a new strain. Parazitologiya. 51, 387-398 (in Russian, with English summary).

Ganyukova A.I., Malysheva M.N. and Frolov A.O. 2020a. Life cycle, ultrastructure and hostparasite relationships of Angomonas deanei (Kinetoplastea: Trypanosomatidae) in the blowfly Lucilia sericata (Diptera: Calliphoridae). Protistology. 14 (4), 204-218.

Ganyukova A.I., Zolotarev A.V. and Frolov A.O. 2020b. Geographical distribution and host range of monoxenous trypanosomatid Crithidia brevicula (Frolov et Malysheva, 1989) in the northern regions of Eurasia. Protistology. 14 (2), 70-78.

Hamilton P.T., Votýpka J., Dostalova A., Yurchenko V., Bird N. H., Lukeš J., Lemaitre B. and Perlman S.J. 2015. Infection dynamics and immune response in a newly described Drosophilatrypanosomatid association. MBio. 6, e01356e01315.

$\mathrm{Hu}$ C. and Aksoy S. 2006. Innate immune responses regulate trypanosome parasite infection of the tsetse fly Glossina morsitans morsitans. Mol. Microbiol. 60 (5), 1194-1204.

Kostygov A.Y., Grybchuk-Ieremenko A., Malysheva M.N., Frolov A.O. and Yurchenko V. 2014. Molecular revision of the genus Wallaceina. Protist. 165 (5), 594-604.

Kostygov A.Y., Frolov A.O., Malysheva M.N., Ganyukova A.I., Chistyakova L.V., Tashyreva D., Tesařová M., Spodareva V.V., Režnarová J., Macedo D., Butenko A., d'Avila-Levy C.M., Lukeš J. and Yurchenko V. 2020. Vickermania, gen. nov., trypanosomatids that use two joined flagella to resist midgut peristaltic flow within the fly host. BMC Biology. 18, 187.

Lowne B.T. 1890-1892. The anatomy, physiology, morphology and development of the blowfly (Calliphora Erythrocephala). A study in the comparative anatomy and morphology of Insects; with plates and illustrations executed directly from the drawings of the author. Vol. 1. London.

Malysheva M.N. and Frolov A.O. 1995. The development cycle of the flagellate Proteomonas brevicula (Trypanosomatidae) in predatory bugs of the family Nabidae (Hemiptera). Parazitologiya. 29, 289-297 (in Russian with English summary).

Malysheva M.N., Mamkaeva M.A., Kostygov A.Y., Frolov A.O. and Karpov S.A. 2016. Culture collection of parasitic protists at the Zoological 
Institute RAS (CCPP ZIN RAS). Protistology. 10 (1), 26-42.

Podlipaev S.A. 1990. The world fauna of Trypanosomatidae (Protozoa). Cat. Proc. ZIN AS USSR (in Russian).

Schoener E., Uebleis S.S., Cuk C., Nawratil M., Obwaller A.G., Zechmeister T., Lebl K., Rádrová J., Zittra C., Votýpka J. and Fuehrer H. P. 2018. Trypanosomatid parasites in Austrian mosquitoes. PloS One. 13, e0196052.

Svobodová M., Zidkova L., Čepička I., Oborník M., Lukeš J. and Votýpka J. 2007. Sergeia podlipaevi gen. nov., sp. nov. (Trypanosomatidae, Kinetoplastida), a parasite of biting midges (Ceratopogonidae, Diptera). Int. J. Syst. Evol. Microbiol. 57 (2), 423-432.

Teixeira M.M., Borghesan T.C., Ferreira R. C., Santos M.A., Takata C.S., Campaner M. and Camargo E.P. 2011. Phylogenetic validation of the genera Angomonas and Strigomonas of trypanosomatids harboring bacterial endosymbionts with the description of new species of trypanosomatids and of proteobacterial symbionts. Protist. 162, 503-524.

Týč J., Votýpka J., Klepetková H., Šuláková H., Jirků M. and Lukeš J. 2013. Growing diversity of trypanosomatid parasites of flies (Diptera: Brachycera): frequent cosmopolitism and moderate host specificity. Mol. Phylogenet. Evol. 69, 255-264.

Vinogradova E.B. and Reznik S.Y. 2013. The rate of preimaginal development of the blowfly Calliphora vicina R.-D. (Diptera, Calliphoridae) in natural and laboratory conditions. Entomological review. 92 (1), 3-11.

Votýpka J., d'Avila-Levy C.M., Grellier P., Maslov D. A., Lukeš J. and Yurchenko V. 2015. New approaches to systematics of Trypanosomatidae: criteria for taxonomic (re) description. Trends Parasitol. 31 (10), 460-469.

Wallace F.G. 1966. The trypanosomatid parasites of insects and arachnids. Experimental parasitology. 18 (1), 124-193.

Address for correspondence: Anna Ganyukova. Zoological Institute, Russian Academy of Sciences, Universitetskaya Emb. 1, 199034 St. Petersburg, Russia; e-mail: anna.ganyukova@gmail.com 